\title{
POLIFOSFATOS EM DETERGENTES EM PÓ COMERCIAIS
}

\author{
Viktoria Klara Lakatos Osorio e Wanda de Oliveira \\ Instituto de Química, Universidade de São Paulo, CP 26077, 05513-970 São Paulo - SP
}

Recebido em 18/9/00; aceito em 16/11/00

\begin{abstract}
POLYPHOSPHATES IN COMMERCIAL POWDER DETERGENTS. A didactic experiment is proposed in order to identify inorganic phosphates in home laundry detergents by ascending paper chromatography. Chemical principles related with hard water are also investigated. The role of polyphosphates in detergent formulations is discussed and the softening of hard water by sodium tripolyphosphate is illustrated. Several chemical concepts, related to the daily experience of the students, can be explored in post-lab discussions.
\end{abstract}

Keywords: inorganic phosphates; paper chromatography; detergents.

\section{INTRODUÇÃO}

A ação de limpeza da água melhora bastante com a adição de detergentes. Estas substâncias apresentam um comportamento dualístico em água, em virtude de sua estrutura. São genericamente cadeias hidrocarbônicas longas, em cuja extremidade encontra-se um grupo catiônico, aniônico, anfotérico ou simplesmente um grupo polar. Esse grupo, a "cabeça", é hidrofílica enquanto o restante da cadeia, a "cauda", apolar, repele a água e interage bem com materiais oleosos ${ }^{1-4}$. Tal caráter anfifílico permite aos detergentes remover sujeiras que a água sozinha não removeria.

Para a limpeza do corpo e de roupas, têm sido mais utilizados os detergentes com carga negativa, como é o caso do sabão, cuja fabricação envolve um dos processos químicos mais antigos conhecidos ${ }^{5-8}$.

As matérias primas para a obtenção dos sabões são os óleos vegetais e as gorduras animais, formados por triglicerídios. A hidrólise alcalina destes ésteres naturais produz glicerina e os sabões (sais de sódio ou de potássio de ácidos carboxílicos de cadeia longa ou ácidos graxos). Os sabões apresentam, porém, o inconveniente de não atuar bem em meios ácidos e em águas duras ${ }^{1,9,10}$. Em meio ácido, formam o ácido graxo, insolúvel em água, enquanto as águas duras contêm íons de cálcio, magnésio e ferro que formam precipitados com os ânions carboxilatos dos sabões, produzindo uma escuma que adere a tecidos, pias, banheiras, etc.

Para contornar isso foram desenvolvidos novos produtos, derivados da indústria petroquímica, os chamados detergentes sintéticos, que não apresentam as desvantagens citadas em grau tão acentuado 9 . Os mais utilizados atualmente, em preparados em pó para lavar roupas, são os alquilbenzenossulfonatos de sódio de cadeia linear.

Fosfatos inorgânicos condensados são adicionados aos detergentes em pó, com o objetivo de complexar os íons metálicos responsáveis pela dureza das águas e tornar o meio alcalino, melhorando a ação de limpeza ${ }^{8,11,12}$. Detergentes comerciais típicos da década de 50, por exemplo, continham cerca de $40 \%$ de tripolifosfato de sódio ou uma mistura deste com pirofosfato de sódio ${ }^{13}$.

Com o passar do tempo, a utilização crescente desses produtos de limpeza aliada à aplicação não criteriosa de fertilizantes fosfatados nas lavouras levou ao surgimento de problemas ambientais de poluição de águas. Os fosfatos não atuam como materiais tóxicos no meio ambiente, mas sim como nutrientes. Em águas naturais estagnadas, o resultado é o crescimento excessivo de algas, que pode provocar a eutrofização do manancial ${ }^{11,14,15}$.
Sob a pressão dos ambientalistas, surgiram legislações restringindo a adição de fosfatos em detergentes em diversas regiões do mundo ${ }^{11,16,17}$. Um substituto conveniente e bastante recomendado são as zeólitas, aluminossilicatos trocadores iônicos que abrandam águas duras $2,16,18$.

No Brasil, uma consulta às embalagens de detergentes em pó, nos supermercados, esclarece que poucas marcas contem zeólitas, mas quase todas utilizam fosfatos.

Considerando que ortofosfato e fosfatos condensados podem ser separados e identificados por cromatografia de partição em papel, esta técnica permite verificar se detergentes em pó comerciais contém fosfatos e, em caso afirmativo, identificá-los.

\section{SEPARAÇÃO DE FOSFATOS INORGÂNICOS POR CROMATOGRAFIA EM PAPEL}

A cromatografia em papel, desenvolvida por Consden, Gordon e Martin em $1944^{19}$, é uma técnica simples que utiliza pequena quantidade de amostra e se aplica na separação e identificação de compostos polares e iônicos. O papel, que atua como suporte, contém fibras celulósicas constituídas por milhares de unidades de $\beta$-D-glicose, ligadas entre si por átomos de oxigênio ${ }^{20}$. Como a água apresenta grande afinidade pelos grupos hidroxílicos das unidades de glicose, ela fica retida por pontes de hidrogênio e funciona como a fase estacionária. A fase móvel ou eluente é uma fase líquida menos polar, geralmente constituída por solventes orgânicos miscíveis com água. Trata-se portanto de uma cromatografia planar, líquido-líquido, com fase normal ${ }^{21}$.

Os componentes de uma mistura são separados, na cromatografia em papel, em função do seu deslocamento diferencial, arrastados pela fase móvel e simultaneamente retidos pela água (fase estacionária), de maneira seletiva, dependendo dos coeficientes de partição dos componentes nas duas fases ${ }^{21,22}$.

A aplicação da técnica de cromatografia em papel para a análise de misturas de fosfatos inorgânicos remonta ao início da década de cinqüenta, desenvolvida por dois grupos de pesquisadores, um no Canadá e outro na França ${ }^{13}$. O primeiro desenvolveu um procedimento quantitativo baseado em cromatografia descendente com tempos de separação da ordem de 30 a 40 horas $^{23,24}$. O grupo francês utilizou técnica ascendente em cromatografia bidimensional, com duração de 16 a 24 horas, visando identificação quali e quantitativa ${ }^{25,26}$.

Os fosfatos examinados foram o ortofosfato, $\mathrm{PO}_{4}{ }^{3-} \mathrm{e}$ fosfatos condensados ${ }^{27}$, compreendendo os lineares, de fórmula geral $\left[\mathrm{P}_{\mathrm{n}} \mathrm{O}_{3 \mathrm{n}+1}\right]^{(\mathrm{n}+2)-}$, e os cíclicos, $\left[\mathrm{P}_{\mathrm{n}} \mathrm{O}_{3 \mathrm{n}}\right]^{\mathrm{n}-}$. A figura 1 reune alguns representantes típicos desta classe de compostos. 


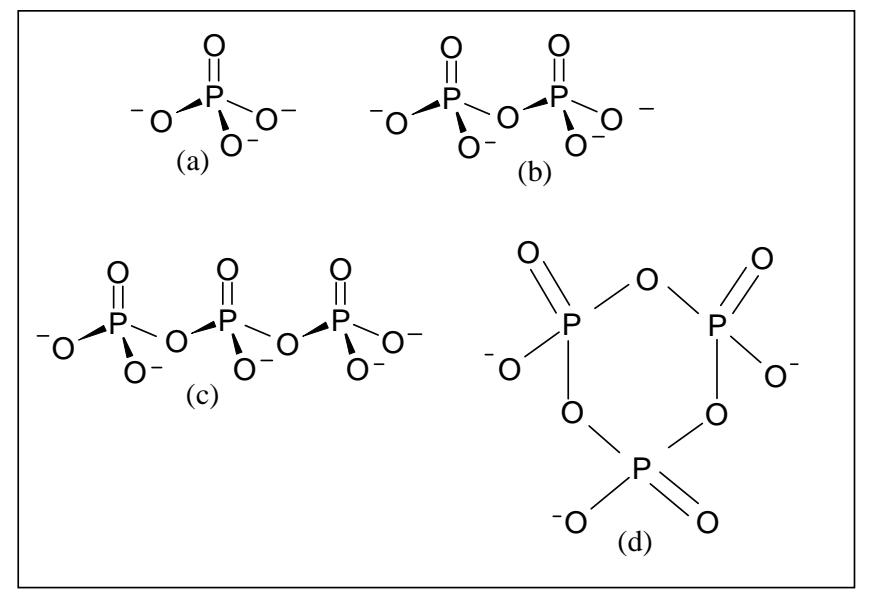

Figura 1. Alguns oxo-ânions do fósforo: (a) ortofosfato, (b) pirofosfato ou dipolifosfato, (c) tripolifosfato, (d) trimetafosfato

$\mathrm{Na}$ separação qualitativa bidimensional, proposta por $\mathrm{Ebel}^{26}$, a primeira etapa emprega um eluente alcalino, contendo álcool iso-propílico, álcool iso-butílico, água e amônia, para separar o conjunto de fosfatos cíclicos dos lineares. A seguir, um eluente ácido, constituído por álcool iso-propílico, ácido tricloroacético, água e uma quantidade pequena de amônia, é aplicado num desenvolvimento a $90^{\circ}$ do anterior, com o objetivo de separar os componentes individuais de cada grupo ${ }^{28,29}$.

Para a separação dos componentes de amostras contendo apenas um tipo de fosfatos, lineares ou cíclicos, o eluente ácido é suficiente.

Bernhart e Chess ${ }^{30}$ testaram várias modificações do eluente ácido de Ebel e concluíram que a substituição do álcool isopropílico por acetona reduziu o tempo de eluição para 2 horas à temperatura ambiente ou 3 horas a $10^{\circ} \mathrm{C}$. Utilizando o eluente com acetona e trabalhando a $10^{\circ} \mathrm{C}$, para diminuir a possibilidade de clivagem por hidrólise das ligações P-O-P, separaram fosfatos lineares e cíclicos de até quatro átomos de fósforo, utilizando apenas cromatografia unidimensional.

Em 1956, Ernesto Giesbrecht trabalhando com Ludwig F. Audrieth, na Universidade de Illinois, iniciou investigações sobre fosfatos e polifosfatos de terras raras ${ }^{31,32}$. Retornando ao Brasil em 1957, Giesbrecht implantou nova linha de pesquisas voltadas para a química do fósforo e de elementos lantanídicos e actinídicos, no então Departamento de Química da Faculdade de Filosofia, Ciências e Letras, atual Instituto de Química, da Universidade de São Paulo ${ }^{33-37}$. Foi o gérmen inicial da pesquisa em química de lantanídios em universidades brasileiras, campo que se desenvolveu e muito contribuiu para que a área Química Inorgânica ganhasse efetiva consistência no panorama nacional ${ }^{38-40}$. Participaram dos trabalhos sobre fosfatos de terras raras Madeleine Perrier ${ }^{41}$, Ebe Barbieri Melardi ${ }^{42-45}$, Osvaldo Antônio Serra ${ }^{46-48}$ e Yoshitaka Gushikem ${ }^{48,49}$, enquanto com Geraldo Vicentini as pesquisas se estenderam para outros metais, como titânio, zircônio, háfnio e tório ${ }^{50,51}$. Para caracterizar as preparações de polifosfatos era utilizada, entre outras, a técnica de cromatografia em papel ${ }^{33}$. Originou-se de tais estudos a incorporação dessa técnica ao elenco de experimentos didáticos da Instituição.

O experimento tornou-se tradicional nas disciplinas de Química Inorgânica do Instituto de Química da USP ${ }^{52}$. Inicialmente visava a caracterização do produto de um outro experimento em que se preparava o tripolifosfafo de sódio ${ }^{53}$. Posteriormente, o objetivo passou a ser a identificação de amostras artificiais constituídas de mistura de fosfatos.

Desde 1995, nas disciplinas de Química Inorgânica para alunos da Escola Politécnica e Química dos Elementos para alunos do Instituto de Química, este experimento foi por nós adaptado para identificar fosfatos inorgânicos presentes em detergentes em pó comerciais e concomitantemente ilustrar alguns princípios relacionados com dureza de águas. O presente artigo relata este experimento didático, os resultados obtidos pelos alunos, bem como testes comparativos efetuados com diferentes fases móveis, visando melhorar as condições de trabalho. São ainda sugeridos vários assuntos correlatos, de natureza interdisciplinar, para discussões pós-laboratório.

\section{PARTE EXPERIMENTAL}

$\mathrm{O}$ experimento requer um período de 3 a 4 horas. Como a climatização da cuba cromatográfica é demorada, o eluente deve ser preparado previamente e colocado na cuba uma hora antes do início da aula. As soluções dos padrões e do revelador também podem ser fornecidas prontas. Os alunos iniciam o trabalho preparando a dispersão aquosa de sua amostra de detergente em pó, aplicam amostra e padrões no papel cromatográfico e o colocam na cuba. O desenvolvimento do cromatograma requer cerca de uma hora. Este intervalo é aproveitado para os testes com águas duras temporária e permanente.

\section{Preparação dos eluentes}

Eluente $\mathbf{A}^{52}$ - Uma solução inicial é preparada, dissolvendo-se $20 \mathrm{~g}$ de ácido tricloroacético $(99 \% \mathrm{~m} / \mathrm{m})$ em $50 \mathrm{~mL}$ de água destilada. Adicionam-se a seguir $2 \mathrm{~mL}$ de hidróxido de amônio concentrado e completa-se o volume a $100 \mathrm{~mL}$ com água destilada. Obtém-se o eluente, misturando $26 \mathrm{~mL}$ dessa solução, $64 \mathrm{~mL}$ de acetona e $10 \mathrm{~mL}$ de água destilada.

Eluente B (eluente ácido de Ebel) ${ }^{26}$ - Misturam-se $75 \mathrm{~mL}$ de álcool iso-propílico, 5,0 g de ácido tricloroacético $(99 \% \mathrm{~m} /$ m) dissolvidos em $25 \mathrm{~mL}$ de água e $0,3 \mathrm{~mL}$ de solução concentrada de amônia.

Eluente $\mathbf{C}^{54}$ - Misturam-se $80 \mathrm{~mL}$ de etanol, 5,0 g de ácido tricloroacético $(99 \% \mathrm{~m} / \mathrm{m})$ dissolvidos em $20 \mathrm{~mL}$ de água e $0,3 \mathrm{~mL}$ de solução concentrada de amônia.

Eluente D - Misturam-se $75 \mathrm{~mL}$ de acetona, 5,0 g de ácido tricloroacético $(99 \% \mathrm{~m} / \mathrm{m})$ dissolvidos em $25 \mathrm{~mL}$ de água e $0,3 \mathrm{~mL}$ de solução concentrada de amônia.

\section{Preparação das soluções das amostras}

Pesam-se 0,10 g de cada amostra padrão e dissolvem-se separadamente em $5 \mathrm{~mL}$ de água destilada. Os padrões são o ortofosfato de sódio $\left(\mathrm{Na}_{3} \mathrm{PO}_{4} .12 \mathrm{H}_{2} \mathrm{O}\right)$, o pirofosfato de sódio $\left(\mathrm{Na}_{4} \mathrm{P}_{2} \mathrm{O}_{7}\right)$ e o tripolifosfato de sódio $\left(\mathrm{Na}_{5} \mathrm{P}_{3} \mathrm{O}_{10} .6 \mathrm{H}_{2} \mathrm{O}\right)$. Para a amostra de detergente em pó, utilizam-se $0,30 \mathrm{~g}$ dispersos em $5 \mathrm{~mL}$ de água destilada. Esta dispersão pode ser utilizada diretamente ou após filtração. Em ordem alfabética, os detergentes investigados foram: ACE, ARIEL, BOLD, CAMPEIRO, MINERVA, OMO, OMO CORES, OMO MÁQUINA, OMO MULTIAÇÃO e POP.

\section{Preparação do revelador ${ }^{52}$}

Dissolve-se 1,50 g de molibdato de amônio em $30 \mathrm{~mL}$ de água destilada. Adicionam-se 1,2 $\mathrm{mL}$ de ácido clorídrico concentrado e $5 \mathrm{~mL}$ de ácido perclórico concentrado e completase o volume a $150 \mathrm{~mL}$ com água destilada.

\section{Climatização da cuba cromatográfica}

Colocam-se cerca de $50 \mathrm{~mL}$ do eluente numa cuba cromatográfica cilíndrica de $20 \mathrm{~cm}$ de altura e $10 \mathrm{~cm}$ de diâmetro. Tampa-se e aguarda-se uma hora. A tampa desta cuba possui, adaptado internamente, um pedaço de bastão de vidro dobrado em U, para a sustentação do papel de cromatografia, num arranjo para técnica ascendente. 


\section{Desenvolvimento do cromatograma}

Num pedaço de papel para cromatografia (Whatman $n^{0} 1$, largura $6,5 \mathrm{~cm}$ e altura $20 \mathrm{~cm}$ ), traça-se, com um lápis, uma linha paralela à base do papel, distando 2 a $3 \mathrm{~cm}$ da mesma. Marcam-se a seguir sobre esta linha quatro pontos onde devem ser aplicadas as soluções das amostras. As amostras são os três padrões e o detergente em pó. Com o auxílio de uma microsseringa, aplica-se num dos pontos 1 a $2 \mu \mathrm{L}$ de uma das soluções, divididos em três a quatro porções. Pode-se também utilizar um capilar e aplicar a solução, de modo a obter uma mancha de 1 a $2 \mathrm{~mm}$ de diâmetro. Seca-se com um jato de ar e fazem-se mais duas aplicações idênticas, nesse ponto. Procedendo de maneira análoga, aplicam-se as outras três soluções, uma em cada ponto, utilizando capilares novos. A seguir coloca-se o papel na cuba, apoiado ao suporte da tampa por uma dobra, presa por um clip de metal, cuidando para que não encoste nas paredes da cuba e apenas a parte do papel abaixo das amostras mergulhe no eluente. Tampa-se a cuba. Após uma hora ou quando o eluente tiver migrado cerca de $10 \mathrm{~cm}$ acima da linha de aplicação das amostras, retira-se o papel da cuba e marca-se rapidamente a frente do eluente. Seca-se o papel na estufa a cerca de $70^{\circ} \mathrm{C}$, durante dois minutos.

\section{Revelação e análise do cromatograma}

Trabalhando na capela, borrifa-se o papel com a solução do revelador, dirigindo o jato nebulizado de baixo para cima. Secase o papel na estufa a $70^{\circ} \mathrm{C}$, durante 2 a 3 minutos. A seguir, revela-se o cromatograma com o auxílio de luz ultravioleta. Delimitam-se as manchas obtidas e determinam-se os seus pontos centrais. Medem-se as distâncias $\left(\mathrm{d}_{\mathrm{i}}\right)$ entre esses pontos e o ponto de aplicação da amostra correspondente, bem como a distância $\left(\mathrm{d}_{\mathrm{m}}\right)$ percorrida pela frente da fase móvel, a partir da linha onde foram aplicadas as amostras. Para uma análise qualitativa do cromatograma, calcula-se, para cada mancha observa$\mathrm{da}$, o fator de retenção, $\mathrm{R}_{\mathrm{f}}$, definido pela expressão:

$$
\mathrm{R}_{\mathrm{f}}=\mathrm{d}_{\mathrm{i}} / \mathrm{d}_{\mathrm{m}}
$$

\section{Preparação das águas duras temporária e permanente}

As águas duras utilizadas são amostras artificiais contendo nitrato de cálcio na concentração aproximada de $6 \times 10^{-3} \mathrm{~mol} \mathrm{~L}^{-1}$. Na água dura permanente adicionou-se $6 \times 10^{-3} \mathrm{~mol}$ de sulfato de sódio e na temporária, $1,2 \times 10^{-2} \mathrm{~mol}$ de bicarbonato de sódio, por litro.

\section{Preparação das soluções de sabão e de detergente}

Para obter a solução de sabão em pedra (ou em barra) dissolve-se $1 \mathrm{~g}$ de raspas de sabão em $10 \mathrm{~mL}$ de etanol e adicionam-se $300 \mathrm{~mL}$ de água destilada. O detergente sintético é um detergente líquido para lavagem de louças, misturado com água na proporção volumétrica de 1:2.

\section{Ensaios efetuados com as águas duras temporária e permanente}

Os alunos efetuam ensaios qualitativos com solução $0,2 \mathrm{~mol} \mathrm{~L}^{-1}$ de oxalato de amônio para verificar a presença de íons de cálcio e com solução $0,2 \mathrm{~mol} \mathrm{~L}^{-1}$ de hidróxido de bário, seguida de solução $1 \mathrm{~mol} \mathrm{~L}^{-1}$ de ácido clorídrico, para identificar o ânion.

O efeito do aquecimento sobre os dois tipos de água dura é também investigado. Os alunos fazem testes de formação de espuma nas águas duras e em água destilada, comparando o desempenho da solução de sabão em pedra com a solução de detergente sintético.

\section{Abrandamento de água dura usando} tripolifosfato de sódio

Uma amostra de água dura permanente é tratada com tripolifosfato de sódio sólido e agitada. Efetua-se a seguir o teste de formação de espuma com sabão em pedra.

\section{RESULTADOS E INTERPRETAÇÃO}

Para a revelação, os cromatogramas são borrifados com uma solução ácida de molibdato de amônio. Inicialmente, é possível visualizar a posição apenas do ortofosfato, pela formação do fosfomolibdato de amônio, $\left(\mathrm{NH}_{4}\right)_{3}\left[\mathrm{P}\left(\mathrm{Mo}_{3} \mathrm{O}_{10}\right)_{4}\right]$, de cor amarela ${ }^{55}$. As posições das manchas correspondentes aos polifosfatos são determinadas após expor o papel à luz ultravioleta, que provoca a formação de azul de molibdênio.

Adicionando-se fosfato a uma solução acidulada de molibdato, forma-se um heteropoliânion:

$\mathrm{HPO}_{4}{ }^{2-}+12 \mathrm{MoO}_{4}{ }^{2-}+23 \mathrm{H}^{+} \rightleftharpoons\left[\mathrm{PMo}_{12} \mathrm{O}_{40}\right]^{3-}+12 \mathrm{H}_{2} \mathrm{O}$

cuja estrutura, denominada estrutura de Keggin, apresenta um grupo tetraédrico $\mathrm{PO}_{4}$ dentro de um envoltório formado for unidades octaédricas $\mathrm{MoO}_{6}$, ligadas entre si pelos átomos de oxigênio dos vértices ${ }^{56,57}$. Uma representação da estrutura de íons de Keggin deste tipo pode ser vista na capa e em artigo recente da revista Química Nova ${ }^{58}$. O íon fosfomolibdato é utilizado em análise de fosfato, porque, por redução em condições brandas, produz uma espécie de valência mista, de coloração azul intensa ${ }^{56,57}$.

\section{Resultados dos cromatogramas com o eluente A}

Primeiramente foi utilizado o eluente A, que contém acetona, por ser o recomendado pela ref. 52, na qual se baseou o experimento proposto. Este eluente é semelhante ao utilizado por Bernhart e Chess ${ }^{30}$. Alguns valores típicos de $\mathrm{R}_{\mathrm{f}}$, obtidos por alunos, são mostrados na Tabela 1. Observa-se que os valores não diferem muito para o piro e o tripolifosfato. A quantidade de amostra aplicada também foi variável, devido a diferentes capilares utilizados. Com amostras maiores, as manchas no cromatograma ficam grandes e alongadas, prejudicando a separação e as medidas das distâncias percorridas. Apesar disso, foi possível verificar a presença de tripolifosfato em todas as amostras de detergente em pó examinadas. Alguns grupos de alunos conseguiram detectar uma mistura de pirofosfato e tripolifosfato.

Observa-se também na Tabela 1 que os valores de $R_{\mathrm{f}}$ dos fosfatos condensados determinados pelos alunos da Escola Politécnica em 1997 tendem a ser mais elevados. Isto provavelmente se deve a um maior teor de água presente no eluente utilizado naquele ano. A influência da água nos resultados destes experimentos é discutida no tópico a seguir.

\section{Comparação entre eluentes}

Procurando melhorar os resultados, foram efetuados testes utilizando o eluente A e mais outros três. O eluente B é a fase móvel recomendada por $\mathrm{Ebel}^{26}$, que utiliza como solvente não aquoso o álcool iso-propílico. $\mathrm{O}$ eluente $\mathrm{C}$ foi escolhido por conter etanol, mais disponível em laboratórios didáticos do que o álcool iso-propílico e por ter sido utilizado em cromatografia de fosfatos ${ }^{54}$. Finalmente, o eluente D, semelhante ao de Ebel, substituindo o álcool iso-propílico por acetona, foi testado por conter maior teor de acetona do que o eluente A.

A Tabela 2 apresenta dados comparativos dos quatro eluentes e os valores de $R_{f}$ dos fosfatos investigados, incluindo dados da literatura ${ }^{13,59}$. Substituindo o álcool iso-propílico (eluente B) por acetona (eluente D), reduz-se a cerca de um 
Tabela 1. Resultados dos alunos para valores de $\mathrm{R}_{\mathrm{f}}$ de fosfatos em detergentes em pó comerciais. Eluente = acetona - água - ácido tricloroacético $20 \% \mathrm{~m} / \mathrm{v}-\mathrm{NH}_{3}$ conc. $(64 \mathrm{~mL}: 10 \mathrm{~mL}: 26 \mathrm{~mL}: 0,5 \mathrm{~mL})$

\begin{tabular}{cccccc}
\hline Turma/Ano & \multicolumn{3}{c}{ Rf dos padrões } & Detergente \\
\hline & $\mathrm{PO}_{4}{ }^{3-}$ & $\mathrm{P}_{2} \mathrm{O}_{7}{ }^{4-}$ & $\mathrm{P}_{3} \mathrm{O}_{10}{ }^{5-}$ & Amostra & $\mathrm{R}_{\mathrm{f}}$ \\
\hline IQUSP/1995 & 0,83 & 0,63 & 0,50 & I & 0,50 \\
& 0,80 & 0,60 & 0,40 & I & 0,44 \\
IQUSP/1997 & 0,85 & 0,67 & 0,48 & II & 0,48 \\
& 0,86 & 0,66 & 0,53 & III & 0,54 \\
POLI/1997 & 0,84 & 0,67 & 0,54 & III & 0,44 \\
& 0,82 & 0,63 & 0,46 & IV & 0,61 \\
POLI/1998 & 0,84 & 0,74 & 0,64 & III & 0,60 \\
& 0,83 & 0,70 & 0,60 & III & 0,56 \\
POLI/1999 & 0,77 & 0,67 & 0,56 & III & 0,38 \\
& 0,88 & 0,57 & 0,44 & IV & 0,$59 ; 0,45$ \\
& 0,84 & 0,68 & 0,45 & IV & 0,$67 ; 0,42$ \\
& 0,86 & 0,66 & 0,45 & IV & 0,44 \\
& 0,83 & 0,61 & 0,48 & V & 0,52 \\
& 0,81 & 0,67 & 0,57 & VI & 0,48 \\
\end{tabular}

Tabela 2. Influência do eluente nos valores de $\mathrm{R}_{\mathrm{f}}$ de fosfatos.

\begin{tabular}{lcccc}
\hline Eluente $^{\mathrm{a}}$ & Tempo $^{\mathrm{b}} / \mathrm{min}$ & \multicolumn{3}{c}{ Valores de $\mathrm{R}_{\mathrm{f}}{ }^{\mathrm{c}}$} \\
\hline & & $\mathrm{PO}_{4}{ }^{3-}$ & $\mathrm{P}_{2} \mathrm{O}_{7}{ }^{4-}$ & $\mathrm{P}_{3} \mathrm{O}_{10}{ }^{5-}$ \\
\hline $\mathrm{A}$ & 60 & $0,83-0,85$ & $0,63-0,66$ & $0,48-0,50$ \\
$\mathrm{~B}$ & 170 & $0,70-0,71$ & $0,40-0,49$ & $0,25-0,28$ \\
$\mathrm{~B}$ (ref. 59) & & 0,69 & 0,44 & 0,29 \\
$\mathrm{~B}$ (ref. 13) & 115 & $0,68-0,73$ & $0,42-0,48$ & $0,21-0,33$ \\
$\mathrm{C}$ & 50 & $0,80-0,81$ & $0,59-0,69$ & $0,44-0,49$ \\
$\mathrm{D}$ & $0,75-0,78$ & $0,49-0,55$ & $0,25-0,29$ \\
\hline
\end{tabular}

${ }^{\mathrm{a}} \mathrm{A}=$ acetona - água - $\mathrm{Cl}_{3} \mathrm{CCOOH} 20 \% \mathrm{~m} / \mathrm{v}-\mathrm{NH}_{3}$ conc. $(64 \mathrm{~mL}: 10 \mathrm{~mL}: 26 \mathrm{~mL}: 0,5 \mathrm{~mL}) ; \mathrm{B}=$ iso-propanol - água - $\mathrm{Cl}{ }_{3} \mathrm{CCOOH}$ $99 \% \mathrm{~m} / \mathrm{m}-\mathrm{NH}_{3}$ conc. $(75 \mathrm{~mL}: 25 \mathrm{~mL}: 5,0 \mathrm{~g}: 0,3 \mathrm{~mL}) ; \mathrm{C}=$ etanol - água $-\mathrm{Cl}_{3} \mathrm{CCOOH} 99 \% \mathrm{~m} / \mathrm{m}-\mathrm{NH}_{3}$ conc. $(80 \mathrm{~mL}: 20$ $\mathrm{mL}: 5,0 \mathrm{~g}: 0,3 \mathrm{~mL}) ; \mathrm{D}=$ acetona - água $-\mathrm{Cl}_{3} \mathrm{CCOOH} 99 \% \mathrm{~m} / \mathrm{m}-\mathrm{NH}_{3}$ conc. $(75 \mathrm{~mL}: 25 \mathrm{~mL}: 5,0 \mathrm{~g}: 0,3 \mathrm{~mL}) ;{ }^{\mathrm{b}} \mathrm{Tempo}$ necessário para o eluente percorrer $10 \mathrm{~cm}$, a partir do ponto de aplicação das amostras; ${ }^{c}$ As faixas de valores de $R_{\mathrm{f}}$ englobam os resultados de duas ou mais repetições

Tabela 3. Valores de $\mathrm{R}_{\mathrm{f}}$ de fosfatos em detergentes em pó comerciais. Eluente $=$ acetona - água $-\mathrm{Cl}_{3} \mathrm{CCOOH} 99 \% \mathrm{~m} / \mathrm{m}-\mathrm{NH}_{3}$ conc. $(75 \mathrm{~mL}: 25 \mathrm{~mL}: 5,0 \mathrm{~g}: 0,3 \mathrm{~mL})$

\begin{tabular}{|c|c|c|c|c|c|c|c|c|c|}
\hline & \multicolumn{9}{|c|}{ Detergentes } \\
\hline & Padrões & III & IV & $\mathrm{V}$ & VI & VII & VIII & IX & $\mathrm{X}$ \\
\hline $\mathrm{R}_{\mathrm{f}}\left(\mathrm{PO}_{4}{ }^{3-}\right)$ & 0,75 & $0,77^{\mathrm{a}}$ & $0,72^{\mathrm{a}}$ & $0,70^{\mathrm{a}}$ & $0,70^{\mathrm{a}}$ & nd & $0,71^{\mathrm{a}}$ & $0,71^{\mathrm{a}}$ & nd \\
\hline $\mathrm{R}_{\mathrm{f}}\left(\mathrm{P}_{2} \mathrm{O}_{7}^{4-}\right)$ & 0,49 & 0,52 & 0,51 & 0,50 & 0,44 & $0,51^{\mathrm{a}}$ & 0,52 & 0,48 & nd \\
\hline $\mathrm{R}_{\mathrm{f}}\left(\mathrm{P}_{3} \mathrm{O}_{10}{ }^{5-}\right)$ & 0,25 & 0,29 & 0,26 & 0,26 & 0,22 & 0,31 & 0,26 & 0,23 & nd \\
\hline Branqueador óptico & & $\operatorname{sim}$ & não & $\operatorname{sim}$ & $\operatorname{sim}$ & não & $\operatorname{sim}$ & $\operatorname{sim}$ & muito pouco \\
\hline
\end{tabular}

${ }^{\mathrm{a}}$ mancha muito fraca; nd = não detectado

terço o tempo necessário para o desenvolvimento do cromatograma e há um aumento nos valores de $\mathrm{R}_{\mathrm{f}}$ do orto e pirofosfato. Comparando os eluentes A e D, conclui-se que os resultados são melhores com o eluente $\mathrm{D}$, que contém menos água. $\mathrm{O}$ teor de água no eluente afeta profundamente os valores de $\mathrm{R}_{\mathrm{f}}$, como seria de se esperar para uma cromatografia em que a fase estacionária é a água. Com eluentes mais ricos em água, todos os valores de $R_{f}$ se tornam maiores, tendendo a ficar muito próximos e prejudicando a separação ${ }^{26}$.

$\mathrm{O}$ eluente $\mathrm{C}$ não apresenta vantagens em relação aos demais, além de requerer quase o dobro do tempo do que os necessários para os eluentes contendo acetona.

Foram também preparadas e testadas misturas de fosfatos, dois a dois. Assim, a mistura de ortofosfato e pirofosfato foi bem separada pelos eluentes A, B e D. Já a mistura de pirofosfato e tripolifosfato só foi separada satisfatoriamente pelo eluente D.

\section{Comparação entre diferentes marcas de detergentes em pó}

Escolhido o eluente D como o mais adequado, foram efetuados cromatogramas de detergentes em pó vendidos no comércio para lavagem de roupa. A aplicação direta da dispersão de detergente em pó ou após a filtração conduziu aos mesmos resultados. A Tabela 3 resume as observações experimentais efetuadas.

Os branqueadores ópticos são evidenciados pela fluorescência azul que apresentam quando expostos à radiação ultra-violeta, durante a revelação. Observou-se que o produto especial para roupas coloridas não contém esse aditivo. 
Com uma única exceção, os produtos examinados apresentaram pirofosfato e tripolifosfato. A presença de traços de ortofosfato pode ser atribuída à hidrólise dos fosfatos condensados, por ex.:

$$
\mathrm{P}_{3} \mathrm{O}_{10}{ }^{5-}(\mathrm{aq})+\mathrm{H}_{2} \mathrm{O}(\mathrm{l}) \rightleftharpoons \mathrm{HPO}_{4}{ }^{2-}(\mathrm{aq})+\mathrm{HP}_{2} \mathrm{O}_{7}{ }^{3-}(\mathrm{aq})
$$

Esta reação pode ocorrer durante o processamento industrial ou durante a manipulação da amostra no laboratório, principalmente quando se utiliza ar quente para a secagem da solução aplicada no papel.

\section{Estudo de águas duras e abrandamento usando tripolifosfato de sódio}

As águas duras temporária e permanente diferem entre si quanto aos ânions presentes. A primeira contém bicarbonato e a segunda, sulfato ${ }^{60,61}$.

A dureza temporária recebe este nome porque, contrariamente à permanente, pode ser abrandada por aquecimento ${ }^{61}$. A fervura elimina o gás carbônico ${ }^{61,62}$ produzido na reação de decomposição do bicarbonato, deslocando o equilíbrio no sentido de formar produto pouco solúvel que pode ser removido por filtração ou decantação.

$\mathrm{Ca}^{2+}(\mathrm{aq})+2 \mathrm{HCO}_{3}{ }^{-}(\mathrm{aq}) \rightleftharpoons \mathrm{CaCO}_{3}(\mathrm{~s})+\mathrm{CO}_{2}(\mathrm{~g})+\mathrm{H}_{2} \mathrm{O}(\mathrm{l})$

As águas duras caracterizam-se pela dificuldade em produzir espuma com sabões. Adicionando-se sabão em pedra à água dura forma-se inicialmente um produto gelatinoso, menos denso do que a água. Apenas com excesso de sabão, obtém-se espuma. Em presença dos íons metálicos da água dura, formam-se carboxilatos insolúveis ${ }^{62}$, como por exemplo, o estearato de cálcio, consumindo o sabão:

$$
\mathrm{Ca}^{2+}(\mathrm{aq})+2 \mathrm{CH}_{3}\left(\mathrm{CH}_{2}\right)_{16} \mathrm{COO}^{-}(\mathrm{aq}) \rightleftharpoons \mathrm{Ca}\left(\mathrm{C}_{18} \mathrm{H}_{35} \mathrm{O}_{2}\right)_{2}(\mathrm{~s})
$$

Enquanto esses cátions não forem totalmente removidos não se forma espuma ${ }^{60}$, o que representa um desperdício no uso do sabão.

Se a água for tratada com tripolifosfato, não ocorre a precipitação e o sabão adicionado espuma. $\mathrm{O}$ tripolifosfato, cuja estrutura $^{63}$ se encontra representada na figura $1(\mathrm{c})$, forma complexos solúveis com os cátions causadores da dureza, eliminando estes interferentes.

\section{TÓPICOS PARA DISCUSSÃO}

Este experimento permite discussões pós-laboratório muito abrangentes. Além dos temas diretamente envolvidos, podem ser abordados diversos assuntos correlatos, muitos dos quais envolvem o cotidiano do estudante. Seguem sugestões, com remissões à literatura didática onde mais informações podem ser encontradas.

\section{Óleos e gorduras}

De acordo com a classificação de Bloor para os lipídeos, óleos e gorduras são triésteres de ácidos graxos com o 1,2,3triidroxipropano ou glicerol, ou seja, são triacilgliceróis ou triglicerídios ${ }^{64}$. Entre as diversas funções que desempenham $^{65,66}$, estas substâncias atuam como armazenadores de energia para animais e plantas, por isso as sementes são ricas em óleos ${ }^{67}$. Elas precisam sustentar o embrião em desenvolvimento até a sua auto-suficiência ${ }^{68}$.

Os óleos e gorduras naturais contem misturas relativamente complexas de triacilgliceróis, cujas propriedades físicas, químicas e nutricionais dependem da natureza, do número de átomos de carbono e da posição dos grupos acila presentes nas moléculas ${ }^{69}$. Os ácidos graxos esterificados nestes compostos são monocarboxílicos, $\mathrm{RCO}_{2} \mathrm{H}$, onde $\mathrm{R}$ representa cadeias não ramificadas, e possuem número total de átomos de carbono quase sempre par, por serem sintetizados a partir de unidades de dois carbonos ${ }^{64,69}$. Eles podem ser saturados ou insaturados, com uma ou mais ligações duplas, usualmente em configuração cis $^{70}$.

As gorduras são geralmente sólidas, em decorrência de conterem maior proporção de grupos acila saturados, com $10 \mathrm{ou}$ mais átomos de carbono, enquanto os óleos ocorrem como líquidos à temperatura ambiente, por apresentarem maior número de ligações duplas por molécula ${ }^{68-71}$. Os óleos fundem em temperaturas mais baixas porque a presença de ligações duplas em geometria cis diminui a flexibilidade das cadeias carbônicas e atrapalham o empacotamento das moléculas ${ }^{68,70,71}$.

Tabelas detalhando a ocorrência de ácidos graxos saturados e insaturados em gorduras (manteiga, sebo, banha, gordura de frango) e óleos (oliva, milho, caroço de algodão, soja, linhaça, etc.) podem ser encontradas em diversas fontes, na literatura, entre as quais citam-se as referências 7, 70-74. O óleo de soja comercial, por exemplo, tem uma composição média centrada em cinco ácidos graxos principais: palmítico (16:0), esteárico (18:0), oléico (18:1), linoléico (18:2) e linolênico (18:3), que totalizam mais de $95 \%$ do teor de ácidos graxos do óleo ${ }^{75}$. Os símbolos entre parênteses representam número de átomos de carbono: número de ligações duplas presentes no ácido graxo.

Desde o final da década de oitenta, tem sido bastante enfatizada a importância de privilegiar na dieta os triglicerídios insaturados (particularmente os que contém os chamados ácidos graxos ômega-3), que são mais saudáveis para o sistema cardiovascular do que os saturados ${ }^{7,69-71,76}$.

\section{Saponificação}

A hidrólise de uma gordura por um álcali é denominada saponificação. Os produtos resultantes são o glicerol e os sais alcalinos dos ácidos graxos, chamados de sabões ${ }^{73,77}$. Os processos mais primitivos de fabricação de sabão utilizam gorduras animais (sebo) e cinzas vegetais ${ }^{78}$. O meio alcalino é proporcionado pelos carbonatos de sódio e potássio contidos nas cinzas 1,5 .

Segundo uma antiga lenda romana, o nome sabão ("sapo" em latim, "sapone" em italiano, "soap" em inglês) deriva do monte Sapo, onde eram sacrificados animais. As águas das chuvas arrastavam uma mistura de gorduras dos animais e cinzas de madeira das fogueiras pelas encostas do monte até o solo argiloso beirando o rio Tibre. As mulheres perceberam que essa argila facilitava o seu trabalho de lavagem de roupas, proporcionando maior eficiência com menor esforço ${ }^{8}$.

Os sabões são conhecidos desde muito antes da era cristã, porém o seu uso amplo para limpeza e banho é bem mais recente. Teve um grande impulso no final do século XVIII, quando se reconheceu a existência de microorganismos patogênicos e a necessidade de hábitos de higiene e limpeza para combater a sua proliferação ${ }^{1}$. Aspectos históricos sobre os sabões, sua fabricação e seu uso por diferentes civilizações até os dias atuais são abordados nas referências $1,2,5,6$ e 8 .

Dependendo do álcali utilizado na sua fabricação, obtém-se diferentes tipos de sabões. Os sais de sódio de ácidos graxos, conhecidos como sabões duros, encontram-se na maioria dos sabões em pedra de uso doméstico ${ }^{77,79}$. Os sais de potássio, ou sabões moles, são usados em sabonetes ${ }^{7}$, cremes de barbe$\mathrm{ar}^{4,73,79}$ e sabões líquidos ${ }^{79}$. Os de amônio também são utilizados em sabões líquidos ${ }^{78}$. Os de lítio, com maior caráter covalente, são adicionados a óleos minerais usados como lubrificantes, para torná-los mais espessos (formando os "óleos detergentes") e também se aplicam na fabricação de graxas para motores ${ }^{80}$. Eles impedem o acúmulo de resíduos de carvão e de produtos polimerizados ${ }^{81}$. 
A dureza dos sabões é também influenciada pela natureza dos ácidos, ou seja, a partir de gorduras saturadas obtém-se sabões mais sólidos do que a partir dos óleos insaturados ${ }^{77}$.

Conforme já mencionado na introdução deste artigo, os sabões apresentam problemas quando utilizados para lavagens em águas ácidas (por exemplo, na indústria têxtil) e em águas duras, comuns em cidades abastecidas por mananciais provenientes de terreno calcário.

\section{Detergentes sintéticos}

Uma solução tecnológica para os problemas com o sabão foi desenvolver um novo tipo de moléculas suficientemente semelhantes para apresentarem a mesma ação de limpeza, porém diferentes o bastante para resistirem aos efeitos de ácidos e águas duras.

Os primeiros detergentes sintéticos, desenvolvidos durante a Primeira Guerra Mundial (1914-1918) ${ }^{5}$ eram obtidos a partir de gorduras animais (sebo de boi e de carneiro) e vegetais (de coco), por redução com hidrogênio, formando glicerol e um álcool de cadeia longa, que era a seguir tratado com ácido sulfúrico e neutralizado $^{1,82}$. Tratava-se pois de alquilsulfatos, como por exemplo o laurilsulfato de sódio, $\mathrm{CH}_{3}\left(\mathrm{CH}_{2}\right)_{10} \mathrm{CH}_{2} \mathrm{OSO}_{3}{ }^{-} \mathrm{Na}^{+}$, que ainda é utilizado em pastas de dente, xampus e outros cosméticos ${ }^{1}$.

Nos Estados Unidos, a produção de detergentes para uso doméstico começou no início dos anos trinta, porém só se desenvolveu após a Segunda Guerra Mundial (1939-1945), estimulada pela escassez de óleos e gorduras e pela necessidade militar de agentes de limpeza que atuassem em água do mar, rica em sais minerais ${ }^{8}$.

Surgiram assim os detergentes sintéticos derivados do petróleo, os alquilbenzenossulfonatos ou detergentes ABS. As matérias primas para a sua síntese eram o propileno $\left(\mathrm{CH}_{3} \mathrm{CH}=\mathrm{CH}_{2}\right)$, o benzeno, o ácido sulfúrico e uma base, geralmente carbonato de sódio ${ }^{1}$. Por serem mais baratos, foram produzidos e consumidos em grande escala. Despejados no esgoto e acumulados em rios e estações de tratamento de efluentes, passaram a produzir densas camadas de espuma, gerando um novo problema. Há fotos muito ilustrativas nos livros, tais como o rio Tajo, em Toledo, Espanha ${ }^{83}$ e o rio Bogotá, em Columbia, USA, no início dos anos sessenta ${ }^{1}$, cobertos de espuma. Quem se encontrar em São Paulo e quiser fazer a sua própria foto, pode conseguila no rio Tietê após a queda de nível, na passagem pela barragem de Pirapora, em Santana do Parnaíba ${ }^{84}$.

Tentando solucionar o problema das espumas, descobriu-se que a cadeia alquílica ramificada dos detergentes ABS não era degradada por microorganismos ${ }^{1,10,83}$. Em 1964, os produtores de detergentes nos EUA concordaram voluntariamente em modificar as suas formulações, ocorrendo fato semelhante na Europa Ocidental por volta da mesma época ${ }^{16}$.

Entraram então no mercado os detergentes biodegradáveis, utilizados atualmente, que apresentam uma cadeia alquílica linear, os alquilsulfonatos lineares ou detergentes ASL ${ }^{1,85}$. Um exemplo é o dodecilbenzenossulfonato de sódio, obtido pela reação entre dodeceno $\left(\mathrm{CH}_{3}\left(\mathrm{CH}_{2}\right)_{9} \mathrm{CH}=\mathrm{CH}_{2}\right)$ e benzeno, seguida de sulfonação e neutralização ${ }^{86}$. Essas moléculas são degradadas por microorganismos aeróbicos como a Escherichia coli (uma micrografia eletrônica de varredura dessas bactérias, com ampliação de 42500 vezes, pode ser vista na ref. 1 e outra mais ampliada ainda na ref. 87).

Voltando ao problema do rio Tietê, em 1984 pesquisadores da CETESB coletaram as espumas em Pirapora do Bom Jesus e verificaram, por espectrofotometria no infravermelho, que elas continham o detergente linear ASL, biodegradável e não o de cadeia ramificada, biorresistente ${ }^{88}$. Este resultado concordou com o fato de que, a partir de outubro de 1982, todos os detergentes brasileiros passaram a utilizar os alquilbenzenossulfonatos lineares, biodegradáveis. As espumas que continuam a se formar no rio Tietê, em Pirapora do Bom Jesus, são explicadas pelas más condições desse rio (grandes cargas de poluentes orgânicos e anaerobiose) e pelo pequeno tempo de trânsito entre a capital e a descarga da represa de Pirapora. O problema não decorre do uso de tensoativos inadequados, mas sim da falta de estações de tratamento biológico dos esgotos domésticos gerados na região metropolitana de São Paulo ${ }^{88}$.

\section{Modo de atuação dos detergentes na remoção da sujeira}

A sujeira que adere à pele, roupas e outras superfícies é geralmente de natureza oleosa. São gorduras, ácidos graxos, óleos lubrificantes, que encerram também partículas de pó, fuligem e resíduos de pele $e^{1,9,86}$. A água sozinha não consegue remover esse tipo de impureza, principalmente por causa de sua elevada tensão superficial e ineficiente umedecimento?

Sabões e detergentes sintéticos são agentes de limpeza devido ao seu caráter anfifílico que lhes permite atuar como tensoativos e emulsificantes ${ }^{89}$. O modo de atuação dessas substâncias encontra explicação na química dos colóides ${ }^{9,81}$. A maioria dos textos de caráter geral traz explanações e ilustrações, em diferentes níveis de profundidade, sobre os fenômenos envolvidos. Eles vão desde a formação de micelas em água e o efeito Tyndall (justificativa para o aspecto turvo dessas dispersões) até os mecanismos de interação com materiais oleosos, responsáveis pela remoção da sujeira ${ }^{1-3,6,8,9,73,78,86,89-94}$.

O processo de limpeza é facilitado pela agitação mecânica proporcionada manualmente ou pelas máquinas de $\operatorname{lavar}^{8,9}$.

\section{Aditivos em detergentes em pó comerciais}

Os detergentes comerciais modernos são misturas. O seu componente mais importante é o surfactante ou agente tensoativo, o detergente sintético propriamente dito, que substitui o sabão ${ }^{3}$. Ele não é porém o mais abundante. O seu teor numa caixa de detergente em pó para lavanderia é da ordem de 17 a $32 \%$, em massa, em países da América do Sul ${ }^{16}$. O restante é constituído por aditivos variados, sendo a maior proporção deles, em massa, compostos inorgânicos.

Um componente presente em quantidades apreciáveis (10 a 35\%) é o sulfato de sódio, que atua como carga, aumentando o volume do produto final ${ }^{2,5,16}$ e também facilita o escoamento do pó ${ }^{2}$.

São ainda acrescentadas substâncias alcalinas, como o carbonato de sódio (teores de até $60 \%$ ) e o silicato de sódio (5 a $12 \%$ ), que auxiliam na remoção de sujeitas gordurosas, oleosas e ácidas ${ }^{8}$. O silicato de sódio também protege as partes metálicas das máquinas de lavar contra a corrosão $0^{2,8,16}$.

Outros componentes, adicionados em teores da ordem de $1 \%$ ou menos ${ }^{5,16}$, exercem funções bem específicas, para melhorar o desempenho e a aceitação dos detergentes, num mercado muito competitivo ${ }^{95}$. Os principais são:

a) agentes anti-redeposição (ex. carboximetilcelulose) $)^{2,5,8,9}$, que aderem às fibras do tecido, especialmente de algodão, impedindo a redeposição da sujeira,

b) enzimas (ex. amilase, lipase, protease) para auxiliar na remoção de manchas específicas (amido, gorduras, proteínas) ${ }^{4,8}$,

c) corantes para conferir uma tonalidade azulada ao tecido lavado $^{2,8}$,

d) alvejantes (perborato e percarbonato de sódio) para a remoção de manchas ${ }^{2,8}$,

e) perfumes para caracterizar o produto e tornar o seu uso mais agradável, encobrindo o cheiro do detergente e da sujeira na solução de lavagem ${ }^{8}$,

f) branqueadores ópticos ou brancóforos, que absorvem porção ultravioleta da luz solar e emitem luz azul, aumentando o brilho e a alvura do tecido ${ }^{2,3,5,8,96}$ e mascarando o tom amarelado que pode se desenvolver em tecidos brancos ${ }^{1,9}$. Restou mencionar os aditivos de maior interesse para este artigo - os que promovem o abrandamento das águas duras. Inicialmente foram utilizados fosfatos inorgânicos condensados, conforme comentado a seguir. 


\section{Fosfatos inorgânicos em detergentes}

Em 1946, foram lançados os detergentes contendo fosfatos inorgânicos ${ }^{8}$. Os mais utilizados foram primeiramente o pirofosfato de sódio $\left(\mathrm{Na}_{4} \mathrm{P}_{2} \mathrm{O}_{7}\right)$ e depois o tripolifosfato de sódio $\left(\mathrm{Na}_{5} \mathrm{P}_{3} \mathrm{O}_{10}\right)^{12}$. Eles facilitam a atuação do detergente em águas duras, pois atuam como agentes sequestrantes, formando complexos estáveis e solúveis com os cátions causadores de dureza da água ${ }^{11,12,85,97}$.

Além disso, proporcionam alcalinidade à solução, facilitando a limpeza ${ }^{12,98}$

$$
\mathrm{P}_{3} \mathrm{O}_{10}{ }^{5-}(\mathrm{aq})+\mathrm{H}_{2} \mathrm{O}(\mathrm{l}) \rightleftharpoons \mathrm{HP}_{3} \mathrm{O}_{10}{ }^{4-}(\mathrm{aq})+\mathrm{OH}^{-}(\mathrm{aq})
$$

Durante muitos anos os fosfatos pareceram ser os aditivos perfeitos. O preço acessível, a toxicidade praticamente nula, o fato de não serem corrosivos para metais e a ausência de efeitos nocivos sobre fibras e tecidos tornaram o seu uso muito atraente. O seu único problema é serem excelentes nutrientes para algas e outras vegetações que crescem na superfície de lagos ${ }^{2,11}$.

$\mathrm{O}$ teor de fosfatos nos detergentes, que no início chegava a mais da metade do peso total, foi sendo reduzido em diversas regiões, devido a problemas ambientais, a eutrofização. A partir da década de setenta, surgiram leis restringindo o seu uso, em diversas localidades dos EUA ${ }^{11}$ e em outros países ${ }^{16,17}$. No Brasil, o tripolifosfato de sódio ainda é bastante utilizado em detergentes. Um levantamento feito pela Associação Brasileira de Indústrias Químicas (ABIQUIM) o colocou em sexto lugar de importância nas vendas internas, dentro da categoria de produtos inorgânicos. Ele vem atrás de campeões de venda como o hidróxido de sódio e o cloro, porém antes de produtos importantes como o ácido clorídrico, o ácido fosfórico e o sulfato de alumínio ${ }^{99}$. Em 1998, das 68.275 t/ano de tripolifosfato de sódio produzidas no Brasil, 65.649 se destinaram ao mercado interno, sendo $96 \%$ para a indústria de detergentes ${ }^{99}$.

\section{Problemas ambientais em mananciais de água: eutrofização}

No verão de 1971, o lago Medical, em Washington, se apresentava coberto por uma espessa camada de algas e bactérias e as suas águas se tornaram turvas e verde escuras. Os peixes e plantas aquáticas morreram e foram arrastados pelo vento para as margens, exalando mau cheiro ${ }^{15}$. Este processo de "morte" dos lagos, que levaria centenas de anos para ocorrer naturalmente, é acelerado para poucas décadas devido ao excesso de nutrientes despejados nas suas águas ${ }^{100}$. É a eutrofização. Quem não costuma viajar por nossas estradas e nunca viu um lago eutrófico, pode observar reproduções coloridas de fotos de lagos nessas condições nas ref. 15, 100 e 101.

$\mathrm{O}$ aporte de efluentes, esgotos e fertilizantes de lavouras nas vias hídricas elevam os níveis de nitratos e fosfatos ${ }^{102}$. Em lagos e águas com baixa correnteza, essa supernutrição pode provocar um aumento na população de cianofíceas ou cianobactérias, algas verde azuladas que efetuam fotossíntese. Elas são espécies planctônicas, isto é, vivem soltas na massa d'água. A sua multiplicação excessiva origina o fenômeno chamado floração ${ }^{103}$. A superfície da água fica recoberta por uma camada tão espessa desses organismos, que a luz solar não consegue mais atravessá-la. As algas da parte inferior morrem e passam a sofrer degradação por bactérias aeróbicas ${ }^{15}$. As bactérias se multiplicam e consomem oxigênio para converter compostos orgânicos complexos em espécies mais simples como $\mathrm{CO}_{2}, \mathrm{NO}_{3}^{-}$e $\mathrm{SO}_{4}{ }^{2-}$. Ocorre pois um aumento da demanda biológica de oxigênio (DBO). A quantidade de oxigênio dissolvido na água diminui, às vezes ao ponto em que outros organismos aquáticos não podem mais sobreviver, ocorrendo a morte dos peixes ${ }^{14,83,97,101,102,104}$. Se o conteúdo de oxigênio cair a valores muito baixos, as bactérias anaeróbicas podem assumir o processo de decomposição ${ }^{104,105}$. Ao invés de oxidar a matéria orgânica, estas bactérias efetuam a sua redução. Assim, compostos contendo enxofre são convertidos em substâncias fétidas como $\mathrm{H}_{2} \mathrm{~S}$ e metanotiol, $\mathrm{CH}_{3} \mathrm{SH}$. Compostos nitrogenados são reduzidos a $\mathrm{NH}_{3}$ e aminas que também conferem mau cheiro ${ }^{106}$.

A floração de cianobactérias é particularmente danosa quando envolve espécies que liberam toxinas, causando a mortandade dos peixes, de outros animais e até mesmo de seres humanos. Foi a presença dessas toxinas na água de abastecimento que provocou a morte de 40 pacientes de uma clínica de hemodiálise, em Caruaru, no estado de Pernambuco, no verão de $1996^{103}$.

\section{Substitutos para fosfatos inorgânicos nos detergentes}

Conforme já mencionado, a função principal dos fosfatos inorgânicos nos detergentes é proporcionar o abrandamento das águas duras. O abrandamento, ou seja, a remoção dos cátions causadores da dureza, pode ser conseguido através da formação de complexos solúveis (caso dos polifosfatos) ou por precipitação ou ainda por troca iônica ${ }^{1,8,16}$.

Detergentes com "baixo teor de fosfato" ou "sem fosfato" à disposição no mercado devem conter aditivos que exerçam essa função. Assim, podem ser utilizados carbonatos ou silicatos como substitutos para os fosfatos, embora estes produtos sejam menos efetivos ${ }^{85}$.

O carbonato de sódio causa a precipitação dos cátions, sob a forma de carbonatos ou hidróxidos, por ex.:

$$
\begin{gathered}
\mathrm{Ca}^{2+}(\mathrm{aq})+\mathrm{CO}_{3}{ }^{2-}(\mathrm{aq}) \rightleftharpoons \mathrm{CaCO}_{3}(\mathrm{~s}) \\
\mathrm{CO}_{3}{ }^{2-}(\mathrm{aq})+\mathrm{H}_{2} \mathrm{O}(\mathrm{l}) \rightleftharpoons \mathrm{HCO}_{3}^{-}(\mathrm{aq})+\mathrm{OH}^{-}(\mathrm{aq}) \\
\mathrm{Mg}^{2+}(\mathrm{aq})+2 \mathrm{OH}^{-}(\mathrm{aq})
\end{gathered}
$$

Os precipitados formados parecem ser prejudiciais para as máquinas lavadoras automáticas ${ }^{1}$. Além disso, o excesso de íons carbonato torna as soluções fortemente alcalinas, que são perigosas para o manuseio ${ }^{85}$ e agressivas para a pele e os olhos, podendo também haver sério dano se o detergente em pó for ingerido acidentalmente por crianças ${ }^{1}$.

Outra alternativa para os fosfatos é proporcionada pelos sais sódicos dos ácidos nitrilotriacético e etilenodiaminotetraacético, que atuam como complexantes de íons metálicos. Estes aditivos apresentam também as suas desvantagens, além do preço mais elevado. Eles complexam íons tóxicos como o mercúrio e o chumbo, mantendo-os em solução e consequentemente na cadeia alimentar ${ }^{16,100}$.

Os substitutos mais promissores para os fosfatos são as zeólitas, aluminossilicatos cristalinos que substituem os cátions causadores da dureza por cátions de sódio ${ }^{1,2}$.

$$
\mathrm{Ca}^{2+}(\mathrm{aq})+2 \text { Na-zeólita(s) } \rightleftharpoons 2 \mathrm{Na}^{+}(\mathrm{aq})+\text { Ca-zeólita(s) }
$$

A composição química da zeólita na forma sódica pode ser representada pela fórmula genérica $\mathrm{Na}_{\mathrm{x}}\left\{\left(\mathrm{AlO}_{2}\right)_{\mathrm{x}}\left(\mathrm{SiO}_{2}\right)_{\mathrm{y}}\right\} \mathrm{z} \mathrm{H}_{2} \mathrm{O}$.

Esta aplicação aumentou muito o consumo das zeólitas, uma classe de materiais muito importantes, amplamente utilizados como trocadores iônicos, peneiras moleculares, adsorventes, secantes e catalisadores ${ }^{18,107-109}$. As zeólitas, materiais insolúveis, não servem para uso em detergentes líquidos ${ }^{110}$.

Os anos oitenta foram os de maior crescimento do mercado das zeólitas, à medida que a legislação anti-fosfato criava a necessidade de outros aditivos. Atualmente seu uso se encontra estabilizado nos Estados Unidos e com tendência a crescimento na Ásia, principalmente na China, empenhada em combater problemas com eutrofização ${ }^{110}$. No Japão, já em 1984, as zeólitas constituiam o único aditivo em mais de $90 \%$ dos detergentes consumidos ${ }^{16}$.

Na União Européia, $75 \%$ dos detergentes contém zeólita e $25 \%$ fosfato. A demanda por fosfatos experimenta um aumento em 
função de novas preparações de tripolifosfato de sódio, com propriedades de hidratação rápida, para utilização nos detergentes em tabletes para lavanderia. Os tabletes, uma novidade no mercado, visam evitar a superdosagem no uso dos detergentes ${ }^{110}$.

Nos Estados Unidos, os fosfatos foram banidos dos detergentes em pó para uso doméstico em lavanderia e substituídos por zeólitas, porém continuam sendo adicionados aos produtos para lavadoras de prato automáticas. Estes produtos se apresentam sob três formas distintas: $60 \%$ como pós, $33 \%$ como géis e $7 \%$ como tabletes. Os tabletes contêm o maior teor de fosfato, sob a forma de tripolifosfato de sódio (cerca de 35\%), em relação aos pós $(25$ a $30 \%)$ e aos géis $(15 \text { a } 18 \%)^{110}$.

A solução definitiva e melhor para o problema "fosfato" provavelmente envolva a instalação de sistemas eficientes de tratamento de esgoto, que sejam capazes de remover os fosfatos e outros nutrientes ${ }^{85}$. Um tipo de tratamento para remover fosfatos é a floco-decantação, que utiliza como floculantes cloreto ou sulfato de alumínio ou de ferro(III), em pH 5 a $6^{105,111}$. Entretanto, por ser uma solução dispendiosa ${ }^{100}$, não foi adotada amplamente. A Suécia e a Alemanha figuram entre os países que optaram pela sua implantação ${ }^{17}$.

\section{CONCLUSÕES}

A técnica de cromatografia em papel, utilizando eluente contendo ácido tricloroacético, acetona e água, permite detectar a presença de fosfatos condensados em detergentes em pó comerciais para lavagem de roupas.

Os valores de $R_{f}$ são muito influenciados pela natureza e proporção do solvente orgânico na fase móvel, bem como pelo volume e concentração da substância aplicada. É necessário trabalhar com padrões e amostra simultaneamente, no mesmo cromatograma, para que os resultados sejam comparáveis e a identificação possa ser efetuada.

Aplicando quantidades reduzidas de amostra e utilizando um eluente com menor teor de água, as manchas correspondentes a pirofosfato e tripolifosfato são melhor separadas. O eluente proposto neste trabalho apresenta melhor desempenho do que o recomendado na ref. 52, por conter maior proporção de acetona e menor de água.

A correlação entre os dois conteúdos explorados, a cromatografia dos fosfatos e o estudo de águas duras, é feita verificando a propriedade do tripolifosfato de sódio de abrandar água dura.

A utilização de produtos do comércio aumenta o interesse dos estudantes pelo experimento. Eles são incentivados a trazer de casa as amostras de detergente. A utilização de diferentes marcas é um fator adicional de motivação ao final do experimento, quando são coletados e comparados os resultados dos cromatogramas. É interessante também a reação de muitos alunos ao constatarem a presença dos branqueadores ópticos. Quando descobrem a sua função, sentem-se primeiramente surpresos e depois lesados e comentam as suas descobertas com outros colegas e com familiares.

No relatório que os alunos apresentam sobre o experimento e nas aulas que se seguem podem ser abordados temas correlatos, de natureza multidisciplinar, que envolvem o cotidiano do estudante e contribuem para um aprendizado mais eficiente.

\section{AGRADECIMENTOS}

As autoras agradecem à funcionária Ana Cristina Aparecida Naves Manzela dos Santos, pelo apoio técnico e a todos os estudantes que contribuíram para a coleta de resultados e para a avaliação do experimento.

\section{REFERÊNCIAS}

1. Hill, J. W.; Kolb, D. K.; Chemistry for Changing Times; $7^{\mathrm{a}}$ ed., Prentice Hall; New Jersey, 1995; p 560-571.
2. Snyder, C. H.; The Extraordinary Chemistry of Ordinary Things; $2^{\mathrm{a}}$ ed., John Wiley \& Sons; New York, 1995; p 323-339.

3. Atkins, P. W.; Jones, L. L.; Chemistry - Molecules, Matter and Change; $3^{\mathrm{a}}$ ed., W. H. Freeman and Co.; New York, 1997; p 367, 441-442.

4. Atkins, P. W.; Moléculas; tradução Galembeck, F.; Santos, P. S.; EDUSP; São Paulo, 2000; p 61-64.

5. Vanin, J. A.; Alquimistas e Químicos: o Passado, o Presente e o Futuro; $3^{\mathrm{a}}$ ed., Editora Moderna; São Paulo, 1994; p 49-54.

6. Barbosa, A. B.; Silva, R. R. da; Quim. Nova na Escola $\mathrm{n}^{\circ}$ 2, novembro 1995 , p. 3.

7. Hill, G. C.; Holman, J. S.; Chemistry in Context; $4^{\mathrm{a}}$ ed., Nelson International Editions; Walton-on-Thames, 1995; p 562-563.

8. SDA, The Soap and Detergent Association; http:// www.sdahq.org, maio 2000.

9. Shaw, D. J.; Introdução à Química dos Colóides e de Superfícies; tradução Maar, J. H.; Ed. Edgard Blücher Ltda / EDUSP; São Paulo, 1975; p. 95-98.

10. Lee, J. D.; Química Inorgânica não tão concisa; tradução Toma, H. E.; Araki, K.; Rocha, R. C.; Ed. Edgard Blücher Ltda.; São Paulo, 1999; p 279-280.

11. Stoker, H. S.; Chemistry, a Science for Today; MacMillan; London, 1989; p 383-384, 669-671.

12. Ibidem ref. 10; p 257-258.

13. Karl-Kroupa, E.; Anal. Chem. 1956, 28, 1091.

14. Brady, J. E.; General Chemistry - Principles \& Structure; $5^{\mathrm{a}}$ ed., John Wiley \& Sons; New York, 1990; p 782.

15. Botkin, D. B.; Keller, E. A.; Environmental ScienceEarth as a Living Planet; $3^{\mathrm{a}}$ ed., John Wiley \& Sons; New York, 2000; p 421.

16. Layman, P. L.; Chem. \& Eng. News 1984, 62, 17.

17. Ainsworth, S. J.; Chem. \& Eng. News 1995, 73, 30.

18. Layman, P. L.; Chem. \& Eng. News 1982, 60, 10.

19. Consden, R.; Gordon, A. H.; Martin, A. J. P.; Biochem. J. 1944, 38, 516.

20. Joesten, M. D.; Johnston, D. O.; Netterville, J. T.; Wood, J. L.; World of Chemistry; Saunders Coll. Publ.; Philadelphia, 1991; p 452.

21. Collins, C. H.; Braga, G. L.; Bonato, P. S.; Introdução a Métodos Cromatográficos; $6^{\mathrm{a}}$ ed., Ed. da UNICAMP; Campinas, 1995; p 16, 31.

22. Freemantle, M.; Chemistry in Action; MacMillan; London, 1989; p 235-238.

23. Westman, A. E. R.; Scott, A. E.; Nature 1951, 168, 740.

24. Crowther, J.; Anal. Chem. 1954, 26, 1383.

25. Ebel, J. P.; Volmar, Y.; C. R. Acad. Sci. 1951, 233, 415.

26. Ebel, J. P.; Bull. Soc. Chim. France 1953, 20, 991, 998.

27. Cotton, F. A.; Wilkinson, G.; Advanced Inorganic Chemistry; $4^{\text {a }}$ ed., John Wiley \& Sons; New York, 1980; p 475-477.

28. van Waser, J. R.; Phosphorus and its Compounds; vol. 1, Interscience Publ. Inc.; New York, 1958; p 702-703.

29. Shriver, D. F.; Atkins, P. W.; Langford, C. H.; Inorganic Chemistry; Oxford Univ. Press; Oxford, 1990; p 166.

30. Bernhart, D. N.; Chess, W. B.; Anal. Chem. 1959, 31, 1026.

31. Giesbrecht, E.; Buyers, A. G.; Aldrieth, L. F.; J. Inorg. Nucl. Chem. 1957, 5, 133.

32. Giesbrecht, E.; Aldrieth, L. F.; J. Inorg. Nucl. Chem. 1958, 6, 308.

33. Giesbrecht, E.; J. Inorg. Nucl. Chem. 1960, 15, 265.

34. Giesbrecht, E.; Tese de cátedra; Departamento de Química da Faculdade de Filosofia, Ciências e Letras, Universidade de São Paulo; São Paulo, 1961.

35. Giesbrecht, E.; Anais Assoc. brasil. Quím. 1962, $21,13$.

36. Chagas, A. P.; Toma, H. E.; Quim. Nova 1991, 14, 149.

37. Toma, H. E.; Quim. Nova 1996, 19, 578. 
38. Giesbrecht, E.; Vicentini, G.; Zinner, L. B.; Quim. Nova 1984, 7, 273.

39. Felcman, J; Mangrich, A. S.; Cruz, G. M. da; Mello, P. C.; Tsunoda, M.; Quim. Nova 1989, 12, 379.

40. Cagnin, M. A. H.; Quim. Nova 1991, 14, 219.

41. Giesbrecht, E.; Perrier, M.; Anais Assoc. brasil. Quím. 1960, 19, 121.

42. Giesbrecht, E.; Melardi, E. B.; Anais Acad. brasil. Ciênc. 1963, 35, 527.

43. Giesbrecht, E.; Melardi, E. B.; Anais Acad. brasil. Ciênc. 1964, 36, 275.

44. Melardi, E. B.; Giesbrecht, E.; Anais Acad. brasil. Ciênc. 1965, 37, 221.

45. Giesbrecht, E.; Melardi, E. B.; Anais Assoc. brasil. Quím. 1966, $25,43$.

46. Serra, O. A.; Giesbrecht, E.; J. Inorg. Nucl. Chem. 1968, 30, 793.

47. Serra, O. A.; Tese de doutorado; Departamento de Química da Faculdade de Filosofia, Ciências e Letras, Universidade de São Paulo; São Paulo, 1969.

48. Gushikem, Y.; Giesbrecht, E.; Serra, O. A.; J. Inorg. Nucl. Chem. 1972, 34, 2179.

49. Gushikem, Y.; Tese de doutorado; Instituto de Química, Universidade de São Paulo; São Paulo, 1971.

50. Giesbrecht, E.; Vicentini, G.; Ciênc. Cult. 1961, 13, 239.

51. Giesbrecht, E.; Vicentini, G.; J. Inorg. Nucl. Chem. 1963, $25,893$.

52. Giesbrecht, E. (coordenador); Experiências de Química; Ed. Moderna/EDUSP; São Paulo, 1979; p 208-209.

53. Ibidem ref. 52; p 167.

54. Ibidem ref. $28 ;$ p 416.

55. Vogel, A. I.; A Text Book of Qualitative Chemical Analysis; $3^{\mathrm{a}}$ ed., Longmans; London, 1951; p 295.

56. Ibidem ref. 27; p 857-861.

57. Ibidem ref. 29; p 164.

58. Pergher, S. B. C.; Corma, A.; Fornés, V.; Quim. Nova 1999, 22, 693.

59. Hetler, H.; J. Chromatog. 1958, 1, 389.

60. Quagliano, J. V.; Vallarino, L. M.; Química; tradução Espínola, A.; $3^{\mathrm{a}}$ ed., Guanabara Dois; Rio de Janeiro, 1979; p 710.

61. Ibidem ref. 10; p 169.

62. Kotz, J. C.; Purcell, K. F.; Chemistry \& Chemical Reactivity; Saunders Coll. Publ.; Philadelphia, 1987; p 772-773.

63. Butler, I. S.; Harrod, J. F.; Inorganic Chemistry Principles and Applications; Benjamin/Cummings; Redwood City, California, 1989; p 474.

64. Harper, H. A.; Manual de Química Fisiológica; tradução Magalhães, J. R.; $4^{\mathrm{a}}$ ed., Atheneu Editora; São Paulo, 1977; p 13.

65. Lima, J. R.; Nassu, R. T.; Quim. Nova 1996, 19, 127.

66. Silva, F. A. M.; Borges, M. F. M.; Ferreira, M. A.; Quim. Nova 1999, 22, 94.

67. Seager, S. L; Slabaugh, M. R.; Chemistry for Today General, Organic and Biochemistry; $2^{\mathrm{a}}$ ed., West Publ. Co.; Minneapolis, 1994; p 510.

68. Ibidem ref. 4 ; p 50-55.

69. Vianni, R.; Braz-Filho, R.; Quim. Nova 1996, 19, 400.

70. Ibidem ref. 67; p 507-509.

71. Holum, J. R.; Fundamentals of General, Organic, and
Biological Chemistry; $5^{\text {a }}$ ed., John Wiley \& Sons; New York, 1994; p 566-570.

72. Lima, J. R.; Gonçalves, L. A. G.; Quim. Nova 1994, 17, 392.

73. Peruzzo, T. M.; Canto, E. L. do; Química; Ed. Moderna; São Paulo, 1999; p 319-320.

74. Ibidem ref. 5 ; p 47.

75. Costa Neto, P. R.; Rossi, L. F. S.; Zagonel, G. F.; Ramos, L. P.; Quim. Nova 2000, 23, 531.

76. Braz-Filho, R.; Quim. Nova 1994, 17, 405.

77. Hauptmann, H.; Introdução à Química Orgânica; Editora Renascença S. A.; São Paulo, 1947; p 100-101.

78. Ibidem ref. 20; p 732-733.

79. Ibidem ref. $67 ;$ p 511.

80. Ibidem ref. 10; p 153.

81. Jafelicci Jr., M.; Varanda, L. C.; Quím. Nova na Escola $\mathrm{n}^{\circ}$ 9, maio 1999, p 9.

82. Masterton, W. L.; Slowinski, E. J.; Química Geral Superior; tradução Dias Neto, D. C.; Rodrigues, A. F.; $4^{\mathrm{a}}$ ed., Ed. Interamericana Ltda.; Rio de Janeiro, 1978; p 204.

83. Whitten, K. W.; Gailey, K. D.; Davis, R. E.; General Chemistry with Qualitative Analysis; $4^{\mathrm{a}}$ ed., Saunders Coll. Publ.; Philadelphia, 1992; p 550.

84. Espumas flutuantes, Jornal o Estado de São Paulo 17 nov 1998, p C2.

85. Ibidem ref. $82 ;$ p 258-259.

86. Ibidem ref. 7 ; p 553-555.

87. Ibidem ref. 4; p 100.

88. Castro, N. de; Macedo, R. M. de; Ciênc. Cult. 1986, 38, 693.

89. Ibidem ref. 83 ; p 548-549.

90. Ibidem ref. $22 ;$ p 832-833.

91. Ibidem ref. $14 ;$ p 424.

92. Ibidem ref. $71 ;$ p 572.

93. Donovan, T. R.; Poole, M. C.; Yack, D. J.; Chemicals in Action; $2^{\mathrm{a}}$ ed., Holt, Rinehart and Winston of Canada; Toronto, 1995; p 339.

94. Bittencourt Filha, A. M. B.; Costa, V. G.; Bizzo, H. R.; Quím. Nova na Escola ${ }^{\circ}$ 9, maio 1999, p 43.

95. Greek, B. F.; Chem. \& Eng. News 1990, 68, 37.

96. Ibidem ref. 20; p 737.

97. Ibidem ref. 83; p 923.

98. Ibidem ref. $62 ;$ p 763, 834.

99. Anuário da Indústria Química Brasileira; Associação Brasileira da Indústria Química e de Produtos Derivados ABIQUIM; São Paulo, 1993, ano 20; p 30; 1999, ano 26; p 221-222.

100. Ibidem ref. 93; p 350-351.

101. Ibidem ref. 2 ; p 367-368.

102. Ibidem ref. 22 ; p 437-438.

103. Revista Pesquisa FAPESP, no 53, maio 2000, p 28.

104. Ibidem ref. 82; p 257.

105. Gleisberg, D.; Kandler, J.; Ulrich, H.; Hartz, P.; Angew. Chem., Int. Ed. 1976, 15, 354.

106. Hill, J. W.; Hill, C. S.; Chemistry for Changing Times; $5^{\mathrm{a}}$ ed., Macmillan Publ. Co.; New York, 1988; p 354.

107. Jewur, S. S.; Quim. Nova 1985, 8, 99.

108. Mota, C. J. A.; Quim. Nova 1995, 18, 202.

109. Escobar, F. A. M.; Batista, M. S.; Urquieta-González, E. A.; Quim. Nova 2000, 23, 303.

110. McCoy, M.; Chem. Eng. News 2000, 78, 37.

111. Ibidem ref. 27; p 478. 